\title{
Trends in eating patterns, physical activity and socio- demographic factors in relation to postpartum body weight development
}

\author{
BY AGNETA ÖHLIN AND STEPHAN RÖSSNER \\ Obesity Unit, Karolinska Hospital, and Health Behaviour Research, Karolinska Institute, S-171 76 \\ Stockholm, Sweden
}

(Received 3 August 1992 - Revised 27 May 1993 - Accepted 21 June 1993)

\begin{abstract}
'The Stockholm Pregnancy and Weight Development Study' was conducted to identify risk factors for postpartum weight retention, such as dietary habits, physical activity and socio-demographic factors. The body weight development of 1423 pregnant women was studied prospectively from the beginning of the pregnancy until 1 year postpartum. Data were collected from routine pregnancy records and from questionnaires 6 and 12 months postpartum. Mean weight retention 1 year postpartum was $0.5 \mathrm{~kg}$ compared with the prepregnancy body weight. A 'trend method' was constructed to identify a number of pre-defined major patterns of behaviour. The weight retention 1 year postpartum was greater in women who (a) increased their energy intake during and after pregnancy, (b) increased their snack eating after pregnancy to three or more snacks/d, and (c) decreased their lunch frequency starting during or after the pregnancy. Women who had retained $\geqslant 5 \mathrm{~kg} 1$ year postpartum were more seldom physically active in their leisure time throughout the study period compared with women with a smaller weight gain. Postpartum weight retention correlated negatively with the degree of physical activity in the second half year postpartum. These results indicate that postpartum weight retention is more affected by a change in lifestyle during, and above all after, pregnancy than by factors before pregnancy.
\end{abstract}

Body weight: Dietary intake: Exercise: Pregnancy: Social factors

Increasing interest has been focused on pregnancy as a risk period for overweight development (Sheldon, 1949; Craddock, 1978; Beazley \& Swinhoe, 1979; Heliövaara \& Aromaa, 1981; Newcombe, 1982; Rookus et al. 1987; Greene et al. 1988; Öhlin \& Rössner, 1990; Parham et al. 1990). The role of pregnancy in weight retention and its interaction with other factors needs to be clarified since this may prevent overweight. In a previous paper we reported a mean weight increase of $0.5 \mathrm{~kg} 1$ year postpartum compared with the prepregnancy body weight, but $14 \%$ of subjects gained $5 \mathrm{~kg}$ or more (Öhlin \& Rössner, 1990). We found that a large weight gain during pregnancy, as well as cessation of smoking, resulted in a significant increase in the weight retained postpartum. The correlations between postpartum weight changes and a number of other anthropometric factors on the one hand and estimated milk production on the other were, however, very weak. It is still unclear whether and how dietary habits, physical activity and social factors affect postpartum body weight development.

Pregnancy is often associated with behavioural changes (Baric \& MacArthur, 1977), and a few studies have investigated changes in the mother's diet and degree of physical activity in connection with pregnancy (Nobman \& Adams, 1970; Beal, 1971 a; Svanberg et al. 1985; Schofield et al. 1987). In a group of Swedish women, $43 \%$ made some changes in their eating habits during their pregnancy (Samuelsson et al. 1983). However, these habits have rarely been studied in relation to postpartum body weight development or to the risk of 
postpartum overweight. Weight gain during pregnancy is positively correlated with postpartum weight retention (Abitbol, 1969; Greene et al. 1988; Parham et al. 1990; Öhlin, 1991). Energy intake is often increased in the second half of pregnancy but may be reduced in late pregnancy (Beal, 1971 a). Some authors have found that pregnancy weight gain or fat accretion is correlated with energy intake (Beal, 1971 b; Haworth et al. 1980; Picone et al. 1982; Endres et al. 1987; Langhoff-Roos et al. 1987). Those who did not find this correlation (King et al. 1972; Ancri et al. 1977; Ash, 1986) only measured the energy intake during the third trimester. Therefore, a question that remains to be answered is whether it is possible to prevent postpartum overweight by adequate eating habits and restricted weight gain during pregnancy. Certainly, energy balance and pregnancy-associated weight changes are also affected by many additional factors such as hormonal and psychological changes (Abitbol, 1969; Picone et al. 1982).

The aim of the present study was to investigate whether it was possible to identify eating habits or exercising habits from before, during or after pregnancy, or socio-demographic factors which could predict increased risk of subsequent overweight development.

\section{METHODS}

Study design

The study has been described in detail in our first report on the 'Stockholm Pregnancy and Weight Development Study' (Öhlin \& Rössner, 1990). In summary, the prepregnancy and pregnancy body weight data were collected from routine pregnancy records, and prospectively at the follow-up visits $2 \cdot 5,6$ and 12 months postpartum. Data on selected social factors were collected both from routine records and from questionnaires 6 and 12 months postpartum. Retrospective data concerning eating habits and physical activity were analysed regarding four study periods: before pregnancy, during pregnancy, 1-6 months after pregnancy and 7-12 months after pregnancy.

\section{SUBJECTS}

Initially 2342 women agreed to participate in the study. Data until 2.5 months postpartum were available in 2295 cases. The drop-out rate 1 year postpartum was $38 \%$ ( 872 cases). At the 6-month visit $15 \%$ dropped out and another $23 \%$ at the 12 -month visit postpartum. One probable reason for dropping out was that many women started to work again 9-12 months postpartum. An analysis of the characteristics of the women who dropped out was performed and revealed only minor differences between participants and drop-outs. A total of 1423 women with complete records were included in our study.

The women represented a mixed metropolitan population. Swedish citizens comprised $97 \%$ of the participants, with the remainder mainly from other Nordic countries. Before pregnancy $90 \%$ worked outside the home; $20 \%$ of the participants had returned to work 9 months after delivery, and $42 \% 1$ year postpartum.

\section{Weight measurements}

Each woman was weighed, without shoes and in light indoor clothing, to the nearest $0 \cdot 1 \mathrm{~kg}$ by the maternity clinic staff using the same scales throughout the study. The prepregnancy body weight and the body height were self-reported at the first visit to the maternity clinic. The difference between the body weight 1 year postpartum and the prepregnancy body weight was defined as $\Delta$-weight. All results relate to unadjusted weight change 1 year postpartum (see p. 461). 


\section{Eating habits and physical activity}

The questionnaires included seven questions about diet and two questions about physical activity. The questions were retrospective, of multiple-choice type and usually had four answer alternatives. Each question was answered for each of the four periods of the study: before pregnancy, during pregnancy, $1-6$ and $7-12$ months postpartum. The diet questions concerned: self-perceived meal time regularity; frequency of breakfast, lunch and snacks; frequency of cooked meals; breakfast quality; self-perceived change of meal sizes and/or frequency of snacking (which we consider as a rough estimate of changes in energy intake). The two questions about physical activity concerned activity level at work and in leisure time. We also asked whether the women had received any dietary information during pregnancy.

\section{Construction of trends and scores}

Trends. The aim was to identify groups with substantially different patterns of behaviour during the four study periods, and to compare the mean $\Delta$-weight in these groups. We developed a new method by which it is possible to classify a person from her behaviour during subsequent time-periods. The patterns of behaviour into which the women were classified were called eating trends and exercising trends. Such trends were constructed for six dietary questions and for two questions about physical activity (Table 1). The trends were based on answers given in the questionnaires. Each question was answered four times: for the study periods before pregnancy, during pregnancy, 1-6 months after pregnancy and 7-12 months after pregnancy. For each question there are theoretically $4^{4}$ (i.e. 256) alternative combinations of answers over the four study periods. To lower the number of groups we decided to predefine seven to eight major behavioural patterns or trends for each question, which included most of the possible combinations. Examples of such trends are constant level, temporary decrease, temporary increase, lasting decrease or lasting increase (Figs. 1-3). To do this we, for example, compiled the four-answer alternatives together into only two or three. In some trends we allowed any answer during one of the specific study periods, which is illustrated by a sloping line in Figs. 2 and 3. When the answers from the four study periods of one woman were in accordance with any of the predefined conditions, the computer generated the code for that specific trend. Women whose answers did not fit into any of the predefined trends constituted a separate group. Thus, in each trend a number of different answer combinations were accepted, all of which showed the same major behavioural tendency over the four study periods.

Scores. A second way of analysing the questionnaires was the construction of dietary scores and activity scores. In this way we could make a rough estimate of the overall eating and exercise patterns of each woman. The possible answers to the diet questions were given $0-5$ points, with the alternative closest to the Swedish national recommended dietary allowances given the highest score. The answers to the physical activity questions were given $0-6$ points, with the highest score for the highest degree of physical activity (Table 2). The scores from the dietary questions were summarized in two categories: (1) dietary pattern based on the questions concerning actual breakfast, lunch and snack frequency, and self-perceived meal time regularity (maximum 80 points for the four periods together, i.e. five points $\times$ four questions $\times$ four study periods); and (2) a simplified estimate of dietary quality based on the questions about breakfast quality and frequency of cooked meals (maximum 40 points, i.e. five points $\times$ two questions $\times$ four periods). Two categories of activity scores were also constructed: activity score at work, and activity score in leisure time. The different categories of scores were calculated for each woman, for each study period separately, and for all periods together. Examples of the scoring approach are presented in Table 2. The scores were analysed in relation to postpartum weight changes. 
Table 1. Questions about dietary habits and physical activity for which trends and scores were constructed

\begin{tabular}{|c|c|}
\hline $\begin{array}{l}\text { Questions for which eating trends } \\
\text { and exercising trends were constructed }\end{array}$ & $\begin{array}{l}\text { Category of score, } \\
\text { based on the questions }\end{array}$ \\
\hline $\left.\begin{array}{l}\text { Self-perceived meal time regularity } \\
\text { Frequency of breakfast } \\
\text { Frequency of lunch } \\
\text { Frequency of snacks }\end{array}\right\}$ & Dietary pattern \\
\hline $\begin{array}{l}\text { Frequency of cooked meals } \\
\text { Breakfast quality* }\end{array}$ & Dietary quality \\
\hline $\begin{array}{l}\text { Self-perceived change of meal sizes } \\
\text { and/or frequency of snacking }\end{array}$ & - \\
\hline Physical activity at work & Activity score at work \\
\hline Physical activity in leisure time & Activity score in leisure time \\
\hline
\end{tabular}

* Trends were not constructed for this question.

Table 2. Examples of scoring approach for questions about breakfast habits and physical activity habits

(Each question was answered for each of the four study periods : before pregnancy, during pregnancy, 1-6 months after delivery and 7-12 months after delivery)

\begin{tabular}{|c|c|c|}
\hline & Question/answer alternatives & Score \\
\hline & \multicolumn{2}{|l|}{ Breakfast frequency } \\
\hline & Daily & 5 \\
\hline & Five to six times/week & 4 \\
\hline & $\begin{array}{l}\text { (Decrease from five to seven times/week to zero to } \\
\text { four times/week within one study period) }\end{array}$ & 2 \\
\hline & One to four times/week & 1 \\
\hline & Never & 0 \\
\hline & \multicolumn{2}{|l|}{ Breakfast quality* } \\
\hline & $\begin{array}{l}\text { High (including the three foodstuff groups, } \\
\text { bread, milk, and fruits or vegetables) }\end{array}$ & 5 \\
\hline & Medium (maximum two of the foodstuff groups) & 3 \\
\hline & Low (maximum one of the foodstuff groups) & 0 \\
\hline & \multicolumn{2}{|l|}{ Physical activity at work } \\
\hline & I did not work & 0 \\
\hline & Mostly sitting & 0 \\
\hline & Sitting or standing, some walking & 1 \\
\hline & Walking, some carrying & 4 \\
\hline - & Heavy manual labour & 6 \\
\hline & \multicolumn{2}{|l|}{ Physical activity in leisure time } \\
\hline & Inactive (reading, watching TV) & 0 \\
\hline & $\begin{array}{l}\text { 4-6 h light activity/week } \\
\text { (walking, cycling, gardening) }\end{array}$ & 2 \\
\hline & Regular activity (jogging, gymnastics) & 4 \\
\hline & Regular hard training, competition & 6 \\
\hline
\end{tabular}

* In the questionnaire there were six defined foodstuff groups and women marked the groups that included their breakfast components. 


\section{Socio-demographic factors}

Data were collected concerning age, parity, marital status, living area, occupation, and duration of maternity leave. A reference socio-economic classification was used to transform profession into three social groups (Statistics Sweden, 1984).

\section{Statistical methods}

Data were analysed to find factors that might be related to weight changes of the mother. Weight changes were analysed (a) in a prospective way: the mean weight change ( $\Delta$-weight) and the proportion of women gaining more or less than $5 \mathrm{~kg}$ were calculated in groups selected for different factors; and (b) in a retrospective way: women were classified as gaining more or less than $5 \mathrm{~kg}$, and the frequency of different factors or behaviours in these weight categories were determined.

For each question the mean $\Delta$-weights for the seven to eight alternative trends were compared using one-way analysis of variance and multiple comparisons among means (Tukey's test). Dunnett's test was used a few times when a trend with few participants was compared with the most represented trend. Chi-square analyses were performed on the frequency tables. Regression analyses were used to investigate relationships between $\Delta$ weight and scores. Multiple stepwise regression analyses were performed to estimate which variables most influenced the $\Delta$-weight.

A control study was made to detect whether it was necessary to adjust for covariation between factors. For the group with each separate eating trend and exercising trend we calculated the mean $\Delta$-weight, age, prepregnancy body mass index $\left(\mathrm{BMI} ; \mathrm{kg} / \mathrm{m}^{2}\right)$, estimated milk production and pregnancy weight gain. The means were analysed and no pattern was observed which identified a systematic covariation between the analysed variable and mean $\Delta$-weight in the different trends.

All women gave their informed consent to participate in the study. The study was approved by the Ethical Committee of the Karolinska Institute, and permission to set up a database was obtained from the Swedish Data Inspection Board.

\section{RESULTS \\ Baseline data}

Body weight, body-weight changes and other baseline data of the 1423 women who completed the study are presented in Table 3 . The mean body weight 1 year postpartum was increased by 1.5 (SD 3.6) $\mathrm{kg}$ compared with the prepregnancy body weight ( $\Delta$-weight; $P<0.001)$. After corrections for the predicted age-related weight gain and possible underestimation of prepregnancy weight, as described by us (Öhlin \& Rössner, 1990), the mean weight gain was estimated to be $0.5 \mathrm{~kg}$. At 1 year postpartum $20 \%$ of the women had lost more than $1 \mathrm{~kg}, 23 \%$ changed about $1 \mathrm{~kg}, 43 \%$ gained $1-5 \mathrm{~kg}$ and $14 \%$ had gained at least $5 \mathrm{~kg}$ compared with their prepregnancy weight.

\section{Eating habits}

Early eating habits. None of the identified eating habits before pregnancy could predict risk for increased weight retention. However, weight gain during pregnancy showed weak but statistically significant increases with lowered score for dietary pattern before pregnancy $(r-0.06, P<0.01)$, and during pregnancy $(r-0.06, P<0.05)$, and with dietary quality before pregnancy $(r-0.08, P<0.01)$.

Eating habits throughout the study. Some eating trends were represented in different proportions among women with $\Delta$-weight more or less than $5 \mathrm{~kg}$ (Table 4). These habits 
Table 3. Baseline data from 1423 Swedish women who completed a study of eating patterns and body weight during and after pregnancy*

(Mean values and standard deviation and ranges)

\begin{tabular}{lccc}
\hline \hline & Mean & SD & Range \\
\hline Age (years) & $29 \cdot 7$ & $4 \cdot 7$ & $17-49$ \\
Height (m) & $1 \cdot 665$ & $0 \cdot 058$ & $1 \cdot 49-1 \cdot 83$ \\
Self-reported prepregnancy & $59 \cdot 5$ & $8 \cdot 1$ & $39 \cdot 0-120 \cdot 0$ \\
body wt (kg) & & & \\
BMI before pregnancy $\left(\mathrm{kg} / \mathrm{m}^{2}\right)$ & $21 \cdot 4$ & $2 \cdot 6$ & $15 \cdot 4-43 \cdot 0$ \\
Wt gain during pregnancy $(\mathrm{kg})$ & $14 \cdot 1$ & $4 \cdot 1$ & $-1 \cdot 5-31 \cdot 5$ \\
$\Delta$-weight $\dagger(\mathrm{kg})$ & $1 \cdot 5$ & $3 \cdot 6$ & $-12 \cdot 3-26 \cdot 5$ \\
Adjusted $\Delta$-weight $(\mathrm{kg})$ & $0 \cdot 5$ & & \\
Parity before present pregnancy $(\%)$ & 52 & & \\
0 & 34 & & \\
1 & 11 & & \\
2 & 2 & $526-5250$ \\
$3-4$ & 3446 & 526 \\
\hline
\end{tabular}

* For details, see p. 458.

$\uparrow$ Body-weight change 1 year postpartum compared with the prepregnancy body weight of the 1423 women who completed the study.

Table 4. Factors that were represented in significantly different proportions in a group of women with weight retention $(\Delta$-weight $) \geqslant 5 \mathrm{~kg}$ compared with women with $\Delta$-weight $<5 \mathrm{~kg}$ during and after pregnancy*

\begin{tabular}{|c|c|c|c|}
\hline \multirow[b]{2}{*}{$\begin{array}{l}\text { Wt retention }(\mathrm{kg}) \ldots \\
n \ldots\end{array}$} & \multicolumn{2}{|c|}{$\begin{array}{l}\text { Women following the } \\
\text { described trends }(\%)\end{array}$} & \multirow{2}{*}{$\begin{array}{c}\text { Statistical } \\
\text { significance } \\
\text { of difference } f: P<\end{array}$} \\
\hline & $\begin{array}{r}<5 \\
1234\end{array}$ & $\begin{array}{c}\geqslant 5 \\
189\end{array}$ & \\
\hline \multicolumn{4}{|l|}{ Eating habits } \\
\hline $\begin{array}{l}\text { Perceived increase in meal sizes } \\
\text { and/or frequency of snacking during } \\
\text { and after pregnancy }\end{array}$ & 26 & 37 & 0.01 \\
\hline Breakfast daily throughout the study & 82 & 74 & 0.05 \\
\hline Lunch daily throughout the study & 39 & 29 & 0.05 \\
\hline $\begin{array}{l}\text { Reduction to zero to four lunches/week from } \\
\text { during or after pregnancy until late } \\
\text { follow-up }\end{array}$ & 17 & 24 & 0.01 \\
\hline \multicolumn{4}{|l|}{ Other factors } \\
\hline $\begin{array}{l}\text { Light leisure time physical activity } \\
\text { at least } 4-6 \mathrm{~h} / \text { week } \\
\text { throughout the study }\end{array}$ & 54 & 46 & 0.05 \\
\hline Living in suburbs & 42 & 53 & 0.05 \\
\hline Lower clerk employment & 22 & 36 & 0.05 \\
\hline
\end{tabular}

* For details, see pp. 458-461.

$\dagger$ Chi-square analysis.

cannot all be used as predictors for postpartum weight gain, since the $\Delta$-weight is very variable in each group. The following salient changes were identified : (1) weight gainers $(\Delta$ weight $\geqslant 5 \mathrm{~kg}$ ) more often $(37 \%)$ perceived that they had increased their meal sizes and/or frequency of snacking during and after the pregnancy (a rough estimate of change in energy 


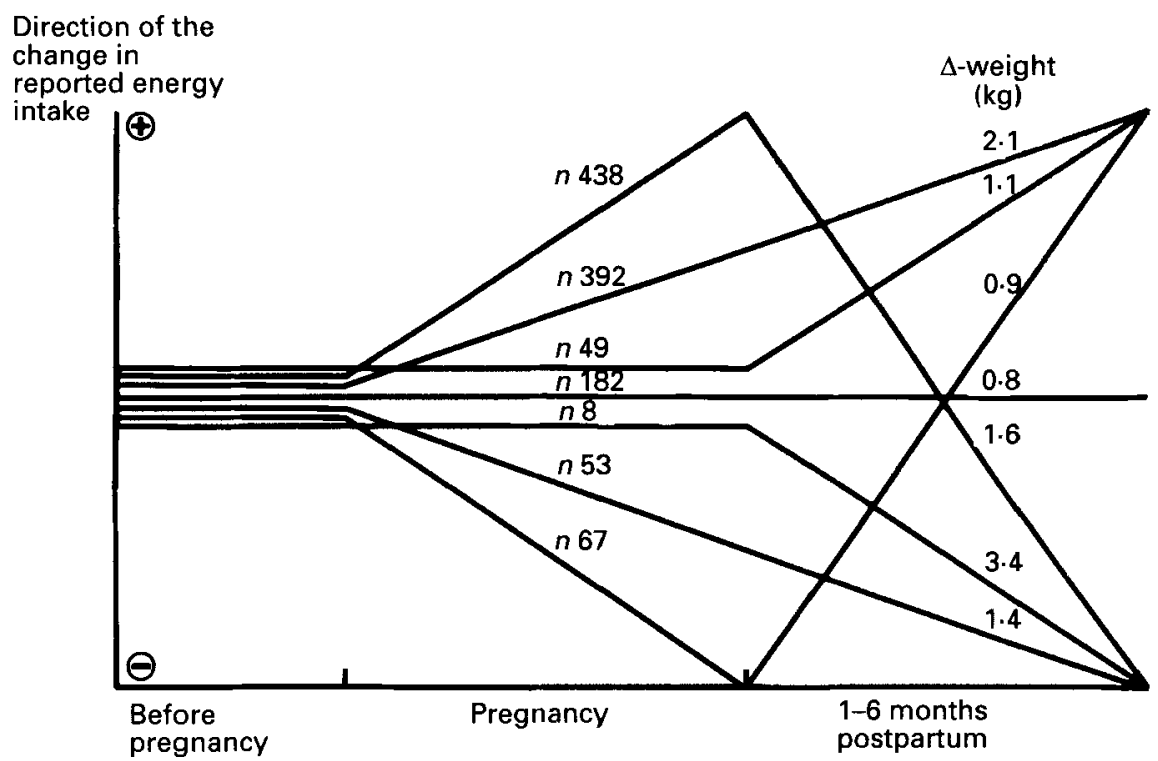

Fig. 1. Mean change in weight $(\Delta$-weight) of women with different self-perceived changes in meal size and/or frequency of snacking (i.e. changes in energy intake) during pregnancy and 1-6 months after the delivery compared with before pregnancy. The trend with a $\Delta$-weight of $3.4 \mathrm{~kg}$ differed significantly from the trends with $0.8 \mathrm{~kg}$ and $0.9 \mathrm{~kg} \Delta$-weight $(P<0.05) . n$, No. of women following each trend.

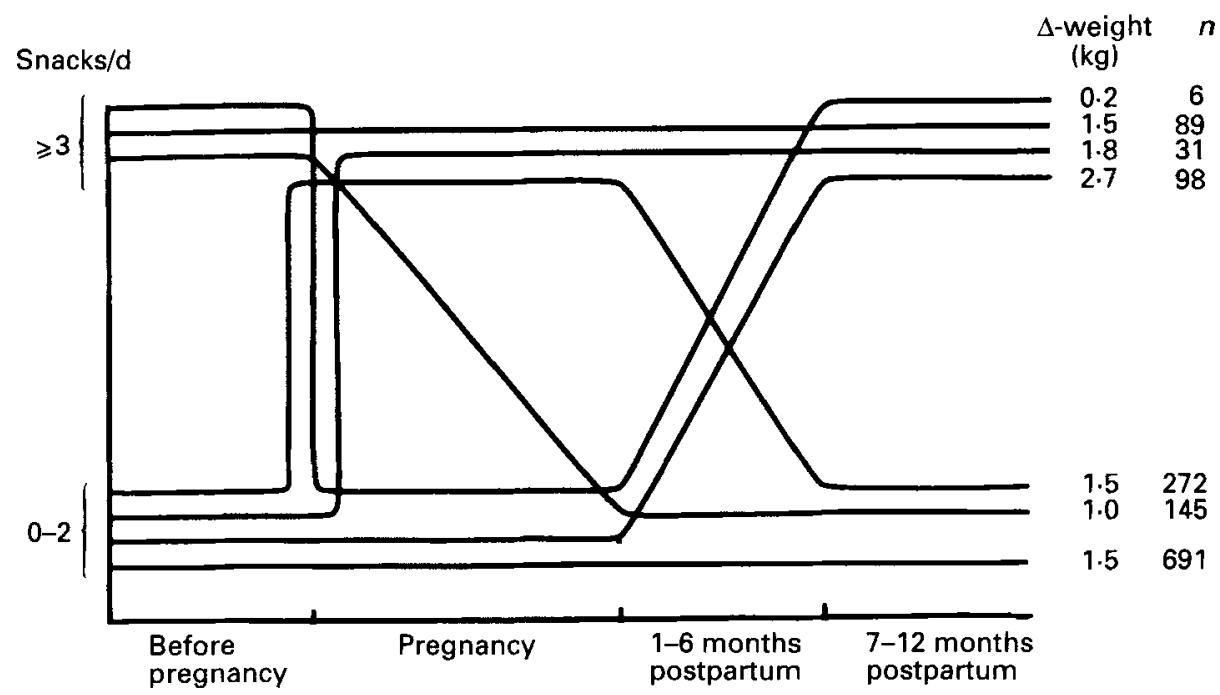

Fig. 2. Mean change in weight ( $\Delta$-weight) of women following six trends of snack-frequency/d during the four study periods. The trend with an increase in snack-frequency postpartum differed significantly in $\Delta$-weight $(2.7 \mathrm{~kg})$, from women who reported none to two snacks all periods, $\Delta$-weight $1.5 \mathrm{~kg}(P<0.05)$. The sloping lines include women with any of the snacking frequencies. $n$, No. of women following each trend.

intake) compared with $26 \%$ of the women with lower $\Delta$-weight. Fig. 1 illustrates the trends of perceived change in energy intake and respective $\Delta$-weight, which did not differ significantly. However, more of the women who reported increased energy intake during and after pregnancy retained $\geqslant 5 \mathrm{~kg}(18 \%)$ than did the women with other trends $(12 \%$; $P<0.01) ;(2)$ the group that reported an increase to $\geqslant$ three snacks $/ d$ after pregnancy had 
Table 5. Scores for dietary pattern and dietary quality from four study periods together, calculated for groups of women with different postpartum weight retentions $(\Delta \text {-weight })^{*}$

\begin{tabular}{|c|c|c|c|c|c|c|}
\hline$\Delta$-weight $(\mathrm{kg}) \ldots$ & $<-5$ & $-5-0$ & $0-<5$ & $5-<10$ & $\geqslant 10$ & $\begin{array}{l}\text { Statistical } \\
\text { significance of } \\
\text { effect of } \dagger:\end{array}$ \\
\hline \multicolumn{7}{|l|}{ Score for dietary } \\
\hline Pattern & 66.9 & $67 \cdot 1$ & $68 \cdot 3$ & $66 \cdot 6$ & $60 \cdot 8$ & $\begin{aligned}-5-0 v & \geqslant 10 P<0.05 \\
0-5 v & \geqslant 10 P<0.01\end{aligned}$ \\
\hline Quality & $30 \cdot 7$ & $31 \cdot 2$ & $31 \cdot 1$ & $31 \cdot 8$ & $30 \cdot 3$ & NS \\
\hline
\end{tabular}

NS, not significant.

* For details of subjects and procedures, see Tables $1-3$ and pp. 458-461.

$\dagger$ One-way analysis of variance and multiple comparison among means.

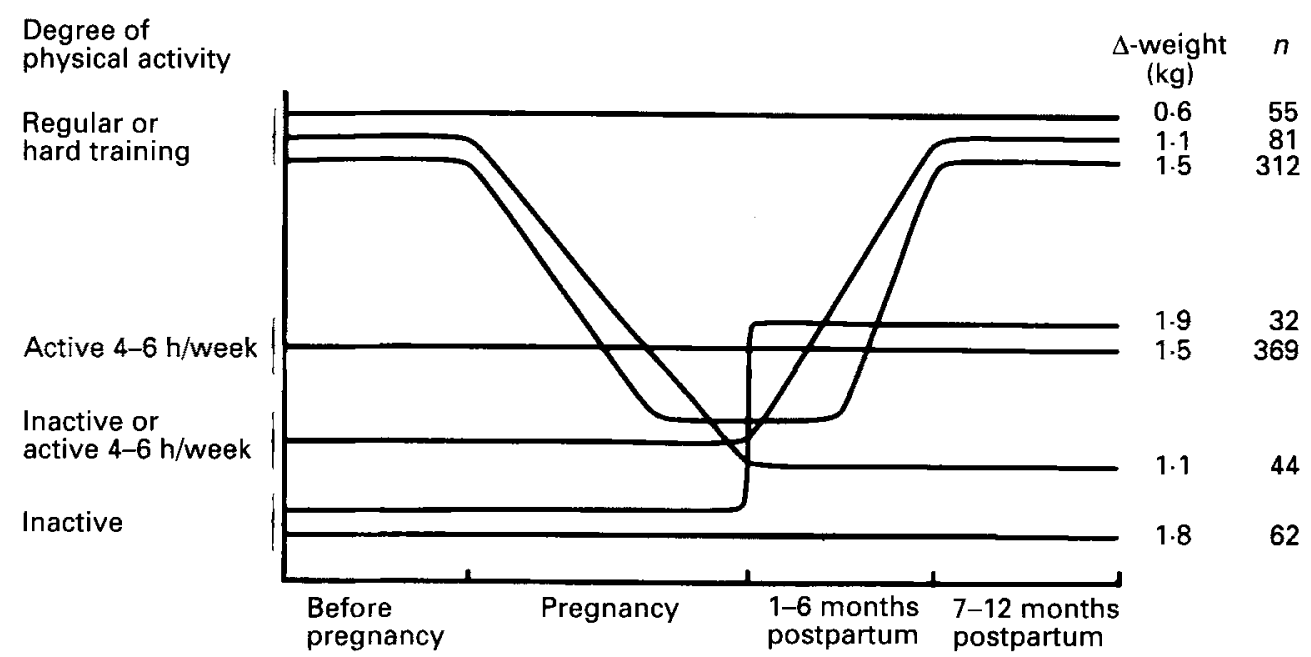

Fig. 3. Mean change in weight ( $\Delta$-weight) of women following seven trends of leisure time physical activity during the four study periods. The mean $\Delta$-weights did not differ significantly between the different trends. The sloping lines include women with both upper or lower degrees of activity. $n$, No. of women following each trend.

a higher $\Delta$-weight $(2.7 \mathrm{~kg})$ than women who reported none to two snacks $/ \mathrm{d}(1.5 \mathrm{~kg})$ through all periods $(P<0.05$; Fig. 2$)$; (3) the weight gainers more often than others reported a decrease in lunch frequency to $0-4$ /week starting during or after pregnancy. Of the women who decreased their lunch frequency as described previously, $18 \%$ retained $\geqslant 5 \mathrm{~kg}$ compared with $11 \%$ of the women who followed alternative trends $(P<0.05)$; (4) fewer of the weight-gainers than other women reported a daily intake of breakfast and lunch during the four study periods; (5) fewer (36\%) of the most pronounced weightgainers with $\Delta$-weight $\geqslant 10 \mathrm{~kg}$ reported regular eating habits during all four study periods, compared with $63 \%$ of the women with lower $\Delta$-weights $(P<0 \cdot 05)$. The score for dietary pattern also showed that the most pronounced weight gainers had more irregular eating habits, by a significantly lower total score (60.8 (SD 10.2) points) compared with women with $\Delta$-weight $\leqslant 5 \mathrm{~kg}$ who had $67 \cdot 1$ (SD 12.1) points $(P<0.05$; Table 5$)$; (6) the $\Delta$-weight correlated weakly but significantly with the score for dietary pattern from 7-12 months postpartum $(r-0 \cdot 07, P<0 \cdot 05)$. 
Table 6. Mean prepregnancy body mass index $\left(B M I ; \mathrm{kg} / \mathrm{m}^{2}\right)$, mean weight retention I year postpartum $(\Delta$-weight) and percentage of women with $\Delta$-weight $\geqslant 5 \mathrm{~kg}$ in groups with different social background*

(Analysis includes 1423 women who completed the study)

\begin{tabular}{|c|c|c|c|c|}
\hline & $n$ & $\begin{array}{c}\text { Prepregnancy } \\
\text { BMI } \dagger\end{array}$ & $\begin{array}{c}\Delta \text {-weight } \\
(\mathrm{kg}) \dagger\end{array}$ & $\begin{array}{c}\text { Percentage with } \\
\Delta \text {-weight } \geqslant 5 \mathrm{~kg} \\
\text { from each group }\end{array}$ \\
\hline \multicolumn{5}{|l|}{ Living area } \\
\hline Inner city & 482 & $21 \cdot 0^{a}$ & $1 \cdot 3$ & $11^{\mathrm{a}}$ \\
\hline Suburb & 615 & $21 \cdot 6^{\mathrm{b}}$ & $1 \cdot 8$ & $16^{\mathrm{b}}$ \\
\hline Countryside & 326 & $21 \cdot 9^{\mathrm{b}}$ & $1 \cdot 4$ & $10^{\mathrm{a}}$ \\
\hline Total & 1423 & & & \\
\hline \multicolumn{5}{|l|}{ Social group $\$$} \\
\hline Group I (highest) & 64 & $21 \cdot 0$ & $2 \cdot 0$ & 16 \\
\hline Group II & 236 & $21 \cdot 3$ & $1 \cdot 8$ & 13 \\
\hline Group III & 146 & $21 \cdot 6$ & $1 \cdot 6$ & 16 \\
\hline Total & 446 & & & \\
\hline \multicolumn{5}{|l|}{ Profession§ $\|$} \\
\hline Unskilled workers & 71 & $21 \cdot 2$ & $2 \cdot 0$ & 18 \\
\hline Skilled workers & 73 & $21 \cdot 7$ & $1 \cdot 0^{\mathrm{a}}$ & 14 \\
\hline Lower clerks & 105 & $21 \cdot 3$ & $2 \cdot 4$ & 22 \\
\hline Clerks middle level & 127 & $21 \cdot 4$ & $1 \cdot 2^{\mathrm{a}}$ & 7 \\
\hline Higher clerks & 48 & $21 \cdot 2$ & $1 \cdot 5$ & 14 \\
\hline Self employed & 6 & $20 \cdot 7$ & $4 \cdot 2^{b}$ & 34 \\
\hline Unemployed/sicklisted & 10 & $21 \cdot 8$ & $2 \cdot 6$ & 20 \\
\hline Students & 46 & $20 \cdot 9$ & $1 \cdot 7$ & 11 \\
\hline Total & 430 & & & \\
\hline \multicolumn{5}{|l|}{ Marital status $\|$} \\
\hline Married or co-habiting & 1244 & $21 \cdot 4$ & 1.6 & 13 \\
\hline Single & 28 & $21 \cdot 9$ & $1 \cdot 6$ & 17 \\
\hline Other & 11 & $21 \cdot 0$ & $0 \cdot 0$ & 0 \\
\hline Married or co-habiting postpartum & 41 & $21 \cdot 0$ & $1 \cdot 5$ & 22 \\
\hline $\begin{array}{l}\text { Married or co-habiting before } \\
\text { pregnancy only }\end{array}$ & 30 & $21 \cdot 8$ & $0 \cdot 7$ & 13 \\
\hline Total & 1354 & & & \\
\hline
\end{tabular}

a.b Within each column, mean values with unlike superscripts were significantly different $(P<0 \cdot 05)$.

* For details of subjects and procedures, see Tables $1-3$ and pp. 458-461.

$\uparrow$ Statistical test with multiple comparison among means (one-way analysis of variance and Tukey's test).

† Statistical test with chi-square analysis.

$\S$ For technical reasons information is available for fewer women.

$\|$ Chi-square analysis not applicable because of different number in the groups.

The mean $\Delta$-weight was not significantly increased in any of the eating trends in the questions concerning meal time regularity, breakfast frequency, lunch frequency, consumption of cooked meals or breakfast composition.

\section{Physical activity}

Groups with different degrees of physical activity in leisure time before pregnancy or at work before pregnancy did not differ in prepregnancy BMI or $\Delta$-weight. Women with different trends of physical activity at work before and during pregnancy did not differ in $\Delta$-weight; nor did women in different $\Delta$-weight categories differ in degree of physical activity at work.

Fewer of the weight-gainers ( $\Delta$-weight $\geqslant 5 \mathrm{~kg}$ ) were physically active in their leisure time 
during all study periods (at least 4-6 h light activity/week) compared with the women with lower $\Delta$-weights (Table 4). Of the most pronounced weight gainers ( $\Delta$-weight $\geqslant 10 \mathrm{~kg}$ ), $23 \%$ were inactive in their leisure time throughout the study, compared with $4 \%$ of the women with lower $\Delta$-weight $(P<0.001)$. Groups with different trends of physical activity in leisure time did not differ significantly in $\Delta$-weight (Fig. 3). Activity score in leisure time during 7-12 months postpartum correlated with $\Delta$-weight $(r-0.05, P<0.05)$.

Slimmers. A total of $13 \%$ of the women reported in the last questionnaire that they had slimmed during the follow-up year. Between 3 and 12 months postpartum these slimmers lost $3.7 \mathrm{~kg}$, while the other women lost $1.7 \mathrm{~kg}$. The slimmers lost their weight mainly during the second 6 months postpartum, while the non-slimmers lost their weight during the first six months. The frequencies of reported behaviour were very similar between the slimmers and the non-slimmers. The only difference was that the slimmers more often had increased their physical activity again after the delivery $(26 \%)$ compared with the other women $(13 \% ; P<0.0001)$.

\section{Socio-demographic factors}

Weight-gainers ( $\Delta$-weight $\geqslant 5 \mathrm{~kg}$ ) more often lived in suburbs near the city than did women with lower weight retention $(P<0.05$; Table 4). Among women living in suburbs near the city the number of weight gainers was larger than among women living in the city or in suburbs far from the city $(P<0.01$; Table 6). A larger proportion of the weight gainers compared with those with a lower $\Delta$-weight were lower clerks $(P<0 \cdot 05)$. Social group, marital status or duration of maternity leave did not identify women with increased risk for weight retention.

\section{Dietary information}

The $\Delta$-weight did not differ between women who had received dietary information during pregnancy $(61 \%)$ and those who did not receive such information.

\section{DISCUSSION \\ Methodological aspects}

The study included a large number of women and this necessitated a simplified dietary survey method. However, the women may not have reported accurately or remembered their dietary habits or degree of physical activity before pregnancy. It is even likely that many women, especially among the overweight, have under-reported their dietary intake or have given an embellished picture of their habits. A consequence of underreporting is that a majority of women might give the same answer in the questionnaire, which makes it impossible to determine whether women in different weight categories have different eating habits. These uncertainties must be remembered when interpreting the results. On the other hand, Callmer et al. (1985) suggest that eating habits are better recalled in connection with pregnancy than during other periods in life.

To our knowledge the construction of eating trends and exercising trends has not been carried out before. The trends gave us the opportunity to categorize women according to general different behavioural changes over time. Scoring systems have been used before (Nobman \& Adams, 1970; Frische et al. 1984; Krebs-Smith \& Clark, 1989; Midtvedt et al. 1990). In the present study they were used in order to obtain an overview of eating habits, combining the answers from different questions at the same time. The regression analysis, however, gave $r$ values too low to make it possible to use these scores as indicators of increased risk for weight gain.

Block (1982) reports that answers to short-method questionnaires show a relatively high correlation coefficient when compared with more detailed dietary survey methods. Similar 
results have been described by Pietinen et al. (1988). It should be possible to develop further both our trend method and our scoring system to give more precise information about eating and exercising habits. Our questionnaire should also be validated in relation to energy balance factors such as body weight. Thereafter it might be possible to use the questionnaires prospectively in the maternity units to identify women at risk of excessive weight retention.

\section{Predictive factors}

Despite the large number of women studied, there were few significant correlations between postpartum weight retention and the analysed eating habits, physical activity and social factors. Possible explanations for the lack of strong predictors for postpartum weight retention could be that (1) our methods may not have been precise enough to identify the relevant habits, (2) dietary habits and physical activity may have been misreported at one or more measurements, (3) the postpartum weight change was very variable, or (4) other factors than those studied here, for instance metabolic, hormonal, social and psychosocial factors, may play a larger role in energy intake, energy balance and weight change.

Some factors were found to have prognostic value, but the explanatory effect was always low. Significant correlations between scores and $\Delta$-weight showed very low $r$ values, indicating that the correlations do not prove nutritional significance. Despite this we cannot exclude the possibility of a true relationship between the factors, even if this method fails to prove it.

Early risk factors. Neither the eating habits nor the level of physical activity before or during the pregnancy could be used as predictors for subsequent weight retention. We found only a non-significant tendency that women who had a physically demanding occupation before pregnancy had a higher $\Delta$-weight, which might be explained by a lowered energy expenditure during and after the pregnancy than while working.

Living in a suburb and being a lower clerk were the only socio-demographic factors that were identified as risk factors for increased weight gain. The association between weight gain and these factors could be due to either a lower level of education or differences in social structure, or that the staff act differently at different maternity clinics. However, social group did not correlate with $\Delta$-weight, and the social group profile was similar in suburbs near and far from the city. In two other studies there were no correlations between educational level and postpartum weight loss (Dugdale \& Eaton-Evans, 1989) or incidence of postpartum obesity (Rimm \& Rimm, 1974).

Long-term risk factors. Physical activity during the follow-up year is of importance for facilitating postpartum weight loss. The degree of leisure time activity might, besides the effect on energy expenditure, also reflect a health consciousness of the woman.

Some eating habits that changed during or after the pregnancy constituted a greater risk for weight retention than eating habits that changed only temporarily during pregnancy and/or a short time after the delivery. These risk habits for postpartum weight retention were: (1) increased meal sizes and/or frequency of snacking during and after pregnancy; (2) increased snack eating after pregnancy to three or more times per d; (3) decreased lunch frequency starting during or after pregnancy. These habits were also more common among women who had gained $\geqslant 5 \mathrm{~kg}$ postpartum than among women with a lower weight retention.

Some trends included only a few women. The largest $\Delta$-weight shown in Fig. 1 was found in a group who reported decreased energy intake, which seems confusing. An individual analysis of these eight women shows that the mean value is considerably increased by one single woman with a $\Delta$-weight of $12 \mathrm{~kg}$. Furthermore, all of them had physically active occupations before pregnancy. This could explain why after pregnancy, without the 
previous physical activity, they had lowered energy expenditure and, therefore, retained weight. For a few of the women the answers concerning snack-frequency or self-perceived change in meal-sizes and/or snack-eating were not consistent.

The largest weight difference shown in Fig. 2 occurred between two groups with similar behaviour over the last three periods, but one trend contained only six women. The weight difference might be explained by the fact that the groups had different behaviour before the pregnancy. The large group that retained $2.7 \mathrm{~kg}$ made a lasting change of habits in increasing their snack-eating after pregnancy, which probably increased their energy intake. The small group returned after the pregnancy to their prepregnancy habits, when energy intake and energy expenditure were balanced and, therefore, weight retention was low.

The $\Delta$-weight was comparably high in some groups with undefined habits (results not presented), but not significantly higher than those in the other trends. This observation could indicate that women with very irregular habits have an increased risk of weight gain. A rather common hypothesis is that an irregular eating pattern and few proper meals might lead to increased snacking or unplanned eating. This usually results in a higher total energy intake (Russ et al. 1984) and increased risk of weight gain.

\section{Dietary information}

Many authors support the idea of giving mothers nutritional advice (Lunell et al. 1969; Samuelsson et al. 1983; Svanberg et al. 1985) since often women are receptive during pregnancy and motivated to make dietary changes (King et al. 1972; Craddock, 1978; Samuelsson et al. 1983; Olsen et al. 1989). In our study dietary information given during pregnancy did not result in a lower weight retention 1 year postpartum. After the delivery many women are very concerned about their weight and try to lose weight (Fidanza \& Fidanza, 1986; Schofield et al. 1987; Abraham, 1989). The postpartum period may be regarded, therefore, as a good time for weight loss, and achieved weight losses tend not to be regained (Craddock, 1978; Bradley, 1989). It is possible that dietary information would have a greater effect if it was given after pregnancy. The mother would maintain some attention and would hopefully be inspired to adapt to favourable dietary and exercising habits.

The authors wish to thank all mothers, midwives and other staff at the maternity units. They thank Dr Ingrid Ursing and Siv Wallmon for valuable help. Elisabeth Berg, Stig Hedman and Brita Barkeling provided excellent statistical and technical assistance. Drs Gunnar Johansson, Gunnar Nordin and Aija Sadurskis are also acknowledged for valuable discussions. The study was supported by the Swedish Council for Planning and Coordination of Research (FRN), and the Stockholm County Council.

\section{REFERENCES}

Abitbol, M. (1969). Weight gain in pregnancy. American Journal of Obstetrics and Gynecology 104, $140-157$. Abraham, S. (1989). Problems with weight control during pregnancy. Medical Journal of Australia 151, 237. Ancri, G., Morse, E. H. \& Clarke, R. P. (1977). Comparison of nutritional status of pregnant adolescents with adult pregnant women. III. Maternal protein and calorie intake and weight gain in relation to size of infant at birth. American Journal of Clinical Nutrition 30, 568-572.

Ash, S. (1986). Energy balance in pregnancy. In Recent Advances in Clinical Nutrition, vol. 2, pp. 109-115 [M. L. Wahlquist and A. S. Truswell, editors]. London: John Libbey.

Baric, L. \& MacArthur, C. (1977). Health norms in pregnancy. British Journal of Preventive and Social Medicine 31, 30-38.

Beal, V. A. (1971a). Nutritional studies during pregnancy. I. Changes in intakes of calories, carbohydrate, fat, protein, and calcium. Journal of the American Dietetic Association 58, 312-320. 
Beal, V. A. (1971 b). Nutritional studies during pregnancy. II. Dietary intake, maternal weight gain, and size of infant. Journal of the American Dietetic Association 58, 321-326.

Beazley, J. M. \& Swinhoe, R. (1979). Body weight in parous women: is there any alteration between successive pregnancies? Acta Obstetrica et Gynecologica Scandinavica 58, 45-47.

Block, G. (1982). A review of validations of dietary assessment methods. American Journal of Epidemiology 4, 492-505.

Bradley, P. J. (1989). Does pregnancy cause obesity? Medical Journal of Australia 151, 543-544.

Callmer, E., Haraldsdottir, J., Löken, J., Seppänen, R. \& Solvoll, K. (1985). Selecting a method for a dietary survey. Näringsforskning 29, 243-252.

Craddock, D. (1978). Obesity and its Management. Edinburgh: Churchill Livingstone.

Dugdale, E. A. \& Eaton-Evans, J. (1989). The effect of lactation and other factors on post-partum changes in body-weight and triceps skinfold thickness. British Journal of Nutrition 61, 149-153.

Endres, J., Dunning, S., Poon, S.-W., Welch, P. \& Duncan, H. (1987). Older pregnant women and adolescents: Nutrition data after enrolment in WIC. Journal of the American Dietetic Association 8, 1011-1019.

Fidanza, A. A. \& Fidanza, R. (1986). A nutrition study involving a group of pregnant women in Assisi, Italy. International Journal for Vitamin and Nutrition Research 56, 373-380.

Frische, G., Olsen, J. \& Jørgensen, F. (1984). Gravides levevaner. Et pilotprojekt om kost, alkohol og tobak (Pregnant womens' habits. A pilot project on diet, alcohol and tobacco). Ugeskrift for Laeger 33, 2497-2500.

Greene, G. W., Smiciklas-Wright, H., Scholl, T. O. \& Karp, R. J. (1988). Postpartum weight change: how much of the weight gained in pregnancy will be lost after delivery? Obstetrics and Gynecology 71, 701-707.

Haworth, J. C., Ellestad-Sayed, J. J., King, J. \& Dilling, L. A. (1980). Fetal growth retardation in cigarette smoking mothers is not due to decreased maternal food intake. American Journal of Obstetrics and Gynecology 137, 719-723.

Heliövaara, M. \& Aromaa, A. (1981). Parity and obesity. Journal of Epidemiology and Community Health 35. 197-199.

King, J. C., Cohenour, S. H., Calloway, D. H. \& Jacobson, H. N. (1972). Assessment of nutritional status of teenage pregnant girls. I. Nutrient intake and pregnancy. American Journal of Clinical Nutrition 25, 916-925.

Krebs-Smith, S. \& Clark, D. (1989). Validation of a nutrient adequacy score for use with women and children. Journal of the American Dietetic Association 89, 775-783.

Langhoff-Roos, J., Lindmark, G.,Kylberg, E. \& Gebre-Medihn, M. (1987). Energy intake and physical activity during pregnancy in relation to maternal fat accretion and infant birth weight. British Journal of Obstetrics and Gynaecology 94, 1178-1185.

Lunell, N.-O., Persson, B. \& Sterky, G. (1969). Dietary habits during pregnancy. A pilot study. Acta Obstetrica et Gynecologica Scandinavica 48, 187-194.

Midtvedt, T., Johansson, G., Carlstedt-Duke, B., Midtvedt, A.-C., Norin, K. E. \& Gustafsson, J.-Å. (1990). The effect of a shift from a mixed diet to a lacto-vegetarian diet on some intestinal microflora associated characteristics. Microbial Ecology in Health and Disease 3, 33-38.

Newcombe, R. G. (1982). Development of obesity in parous women. Journal of Epidemiology and Community Health 36, 306-309.

Nobman, E. D. \& Adams, S. (1970). Survey of changes in food habits during pregnancy. Public Health Reports $85,1121-1127$.

Öhlin, A. (1991). Graviditet och övervikt. En undersökning av faktorer relaterade till viktutveckling efter graviditet hos 1423 kvinnor (Pregnancy and overweight. A study of factors related to postpartum body weight development in 1423 women). PhD Thesis, Karolinska Institute, Stockholm.

Öhlin, A. \& Rössner, S. (1990). Maternal body weight development after pregnancy. International Journal of Obesity 14, 159-173.

Olsen, J., Frische, G., Poulsen, A.O. \& Kirchheiner, H. (1989). Changing smoking, drinking and eating behaviour among pregnant women in Denmark. Evaluation of a health campaign in a local region. Scandinavian Journal of Social Medicine 17, 277-280.

Parham, E. S., Astrom, M. F. \& King, S. H. (1990). The association of pregnancy weight gain with the mothers postpartum weight. Journal of the American Dietetic Association 90, 550-554.

Picone, T. A., Lindsay, H. A., Schramm, M. M. \& Olsen, P. N. (1982). Pregnancy outcome in North American women. I. Effects of diet, cigarette smoking, and psychological stress on maternal weight gain. American Journal of Clinical Nutrition 36, 1205-1213.

Pietinen, P., Hartman, A., Haapa, E., Räsänen, L., Happakoski, J., Palmgren, J., Albanes, D., Virtamo, J. \& Huttonen, J. (1988). Reproducibility and validity of dietary assessment instruments. II. A qualitative food frequency questionnaire. American Journal of Epidemiology 3, 667-676.

Rimm, I. \& Rimm, A. (1974). Association between socioeconomic status and obesity in 59556 women. Preventive Medicine 3, 543-572.

Rookus, M. A., Rokebrand, P., Burema, J. \& Deurenberg, P. (1987). The effect of pregnancy on the body mass index 9 months postpartum in 49 women. International Journal of Obesity 11, 609-618.

Russ, C. S., Ciavarella, P. A. \& Atkinson, R. L. (1984). A comprehensive outpatient weight reduction program: Dietary patterns, psychological considerations, and treatment principles. Journal of the American Dietetic Association 4, 444446. 
Samuelsson, G., Osland-Johansson, T. \& Persson, L.-Å. (1983). Kvinnans kostvanor och näringsintag under graviditet (Dietary habits and nutrient intake during pregnancy). Näringsforskning 27, 22-25.

Schofield, C., Wheeler, E. \& Stewart, J. (1987). The diets of pregnant and post-pregnant women in different social groups in London and Edinburgh: energy, protein, fat and fibre. British Journal of Nutrition 58, 369-381.

Sheldon, J. H. (1949). Maternal obesity. Lancet 6585, 869-873.

Statistics Sweden (1984). Socioekonomisk indelning (SEI). Meddelanden i samordningsfrågor, 1982:4 (Swedish socioeconomic classification. Reports on statistical coordination, 1982: 4). Stockholm, Sweden: Statistiska centralbyrån.

Svanberg, B., Rossander, L. \& Isaksson, B. (1985). Studies of dietary habits in pregnancy - with special reference to the intake of iron. Acta Obstetrica et Gynecologica Scandinavica 48, Suppl., 29-42. 